\title{
Comparison of DSMs Generated Using High Resolution UAV Images in an Archaeological Site
}

\author{
Servet YAPRAK
}

\begin{abstract}
Unmanned Ariel Vehicles (UAVs) are increasingly used for topographic mapping. The use of UAVs in the photogrammetric survey of archaeological sites provides extensive opportunities for the creation of documentation. By using this technology, a detailed and precise digital map of historical and cultural areas can be produced, digital terrain model, orthophotos of the whole area can be produced and inaccessible parts of the historical area such as towers, walls, steep slopes can be documented. For this study, 542 high-resolution images were captured with a UAV from approximately $20 \mathrm{~m}$ high. The high-resolution images were processed using Agisoft Photoscan and Pix4Dmapper Pro software to generate point clouds and Digital Surface Models (DSMs). Both software packages produced GSD values are between 0,401 - 0.425 cm/pixel. When comparing the cross sections obtained from the DSMs obtained from the two software packages, it was seen that the Pix4D software was more successful, especially in the sections produced from surfaces, such as ducts and pits.
\end{abstract}

Keywords: agisoft; Digital Surface Model (DSM); Pix4D; Point Cloud; Unmanned Aerial Vehicle

\section{INTRODUCTION}

In the last decade, aerial and close-range digital photogrammetry has become a potent and widely used tool for three-dimensional topographic modeling [1]. Aerial imagery has long been used in archaeology to get an overhead view of trenches, structures, and to situate sites within the visual and physical landscape. In the past, this has been fulfilled by means of mounting Single-Lens Reflex (SLR) camera on long sticks or other utility vehicles with extendable platforms, or flying hot-air-helium balloons, kites or helicopters. Recently, these topographical modelling difficulties were accomplished using low cost and flexible unmanned platforms, such as Unmanned Aerial Vehicle (UAVs) also called Remotely Piloted Aircraft Systems (RPAS) or Unmanned Aircraft Systems (UAS) [2]. Also, satellites and aircrafts were used to obtain remote images of the Earth's surface, but these instruments did not serve sufficient spatial and temporal solutions [3].

UAVs are a new type of aerial platform for obtaining high-resolution remote sensing measurements of the Earth's surface $[4,5]$. UAVs for monitoring are a technique that provides high-resolution, low-cost and instantaneous data, especially in areas that are inaccessible and have limited coverage. In addition, with the spectral, infrared and thermal cameras and sensors mounted on the UAV platform, a suitable unmanned aerial system is created for remote sensing applications. [6].

UAV-based photogrammetry allows us to obtain multi temporal, multispectral imagery, in a fast, cost-effective and simple approach to real-time acquisition of highresolution geographic information and 3D models from 2D images [7]. Moreover, more commonly it became a tool, which is useful in many ways for archaeological research.

Photogrammetric models are integrated with 3D graphics software packages, allowing the modeling of the old state of the object as it allows data to be interpreted about the structure or object's past state. UAV photogrammetry is extremely useful for creating interpretations in historical sites, calculating volumes, and identifying fine structural elements and ground surface irregularities.
There are many UAV technology applications waiting for the archaeologists of the future. UAVs are not only equipped for cameras that offer traditional images. Depending on the need, Color Infrared (CIR), Near Infrared (NIR) and Forward-Looking Infrared (FLIR) Ultraviolet (UV) and Hyper Spectral (HS) cameras can also be mounted on UAVs to collect remote sensing data that can meet different requirements. IHA images not only provide high-resolution images of the archaeological site, but also provide remote access to information about the location and object dimensions of the archaeological site [8].

Recently, a large number of photogrammetry software has been developed that can automatically correct superimposed images, position them geographically and create dense point clouds. This is called the Structure from Motion (SfM) technique and is based on a principle, which is similar to matched stereo photos. Many researchers [9] have explored recent developments in the use of small UAVs and SfM algorithms. SfM technique is an effectual and cheap topographic measuring tool. This technique uses math and digital design verification to calculate distance, direction of movement, and triangulate surface points. The technique is different from traditional photogrammetry because the camera positions produced from SfM lack the scale and orientation provided by ground control coordinates.

The geometrical accuracy of the georeferenced DTM obtained from UAV images and obtained using SfM photogrammetry depends on several factors, such as the flight plan, the quality of the camera used, camera calibration, SfM algorithms and the accuracy of location information [10].

The 3D surface models, which are generally obtained by SfM photogrammetry, are firstly captured in an arbitrary reference system. Georeferencing comprises converting initial randomly defined spatial data into a predefined coordinate reference system. This is done directly using the known external orientations of the photographs (direct geographic reference) or by referencing the recognizable points (Ground Control Point (GCP) in the photographs). Direct geographic referencing requires measuring the coordinates of the camera as soon 
as the photo is taken. The direct georeferencing method can only be provided within decimeter to meter accuracies [10]. The transformation of the SfM image coordinates to the desired coordinate system is accomplished by $3 \mathrm{D}$ similarity transformation by using several GCPs well distributed in the field whose coordinates have been previously determined precisely. The point cloud produced by SfM can be transferred to other software packages (GIS, 3D modeling) to create a three-dimensional (3D) network or surface model. Today, it has become very easy to create 3D models of the buildings in historical and archaeological sites and preparing their relief plans from the high resolution images obtained from UAV [9].

Light Detection and Ranging (LIDAR) is a new technique used to collect data from the ground and air. LIDAR scanners have been used in recent years UAVs and started to be used extensively. Whether derived from air, mobile or on-site platforms, LIDAR data has become a preferred data source for topographic surveying. It is an active remote sensing technology in which millions of laser pulses are reflected from surfaces and the position of each reflected image is transformed in three dimensions as a point cloud. It has a higher spatial resolution from aerial based and mobile platforms and it has the ability to produce solutions for large areas in a much shorter time than traditional ground-based measurement techniques (total station and GNSS).

Since the laser beam is reflected from the floor of the ground surface, it has the advantage of giving information about the vegetation as it can enter the vegetation canopies. The most important factors affecting LIDAR's sensitivity is the stability of the platform and the scanning density. The more stable the platform and the higher the density of the scanning range, the more accuracy of the topographic model [4].

Aerial LIDAR provides a wider range of information on the surface of the earth with the vertical elevation accuracy at the decimeter accuracy. Ground-Penetrating Radar (GPR) and Electro Magnetic Induction (EMI) technologies are also being carried out using UAVs [11]. The Antenna LIDAR application has gained rapid use since 2000 due to wider hardware availability and the introduction of terrestrial LIDAR systems [12]. Aerial LIDAR, which can penetrate vegetation to provide information under the canopy, is more advantageous than aerial photography. However, penetration can be lost where vegetation is very dense [13].

The accuracy of the orthophoto and DSM obtained depends mainly on the quality of the photos taken and the processing accuracy of the photogrammetric data. It is now possible to obtain high resolution spatial and temporal topographic data at very low cost. Saban explained that DSM quality in a building model depends on the texture information obtained from the roof and the degree of contrast between the roof and the ground surface. Many recent studies evaluate the performance of the processing methods and software solutions produced for the production of geographic-based point clouds or Digital Surface Models. Küng et al. [15] found that the accuracy achieved with Pix4D ${ }^{\circledR}$ software was greatly influenced by the resolution of the pictures taken, the texture of the work area and the terrain structure. Anderson and Gaston [16] compared the quality of DSMs calculated with PhotoScan for different flight heights. Lichti et al. [17] found that the quality of point clouds was greatly influenced by the roughness of the land surface, surface reflection, size and overlap rates. Harwin and Lucieer [18] found that the number and distribution of GCPs had a significant effect on accuracy especially on the area with topographic undulation. They claimed that the best distribution of GCPs was an even distribution across the focal area of the UAV flight height in the range of $1 / 5$ to $1 / 10$, and that GCPs should be closer in steep terrain. All studies show that the accuracy of the results to be obtained depends on the slope of the topography of the land, the sensitivity of the position information of the GCPs and the distribution of GCPs in the field [19].

Docci and Maestri [20] reported that measuring an architectural or archaeological area involves uncovering all the relevant determinants of the state of the structure, rather than just determining the dimensions and shape of the structure. Canciani et al. [21] stated that documentation work requires the collation of archive information about the structure, status determinations, material information, previous applications, and corruption. Producing a map of the work area and a 3D model of objects can be achieved using topographical measurements; however, it is impossible to measure the position of each stone using conventional methods.

Compared with traditional observation methods, the most important advantage of 3D terrain modeling is that the recording quality is greatly improved. Reu et al. [22] claimed that it is extremely necessary and important recording the shapes and textures of archaeological sites in 3D. Doneus et al. [23] found that, unlike traditional recording techniques, archaeological features are, firstly, fully recorded using 3D-shaped, image-based modeling. Secondly, the accuracy to be obtained is quite high and errors that can occur during manual drawing are prevented. Thirdly, the objective record of the excavation, the resulting accuracy, the 3D shape, and the detailed texture makes it possible to revisit the excavation and walk along the excavation surface or along the profiles on the computer. Reu et al [22] stated that all types of measurement could be obtained from computer screens using the 3D model.

In recent years, the application of $3 \mathrm{D}$ recording techniques has increased greatly in archaeological research and documentation studies [24]. Recently, many studies have been conducted using UAV images and SfM techniques for geomorphological studies and land mapping purposes. Harwin and Lucieer [18] reported that a significant point on earth captured from UAV images and SfM techniques can be obtained in the point cloud with an accuracy of $0.025-0.040 \mathrm{~m}$. Lucier et al [25] achieved a high-resolution DSM of Antarctic moss beds from UAV images obtaining an overall RMSE of $0.420 \mathrm{~m}$. Lucier et al [25] used UAV images for mapping landslide displacements. Pavlidis et al. [24] created DEMs and orthophotos in a resolution of $1 \mathrm{~cm}$ resulting in a $R M S E_{X Y}$ of $0.070 \mathrm{~m}$ and a $R M S E_{H}$ of $0.062 \mathrm{~m}$.

\section{CASE STUDY AREA}

The ancient city of Sebastopolis is in the residential area of Sulusaray district, $70 \mathrm{~km}$ south of Tokat city center 
(Lat: 390596N; Long: 36o056E). The new settlement of the district is on the old ancient city. The study area is a Sebastiapolis that combines architectural features such as baths, temples, walls and churches (Fig. 1). The working area is suitable for low UAV flights and 3D models due to its flat topography. The height of the study area is 1010 1030 meters above sea level.

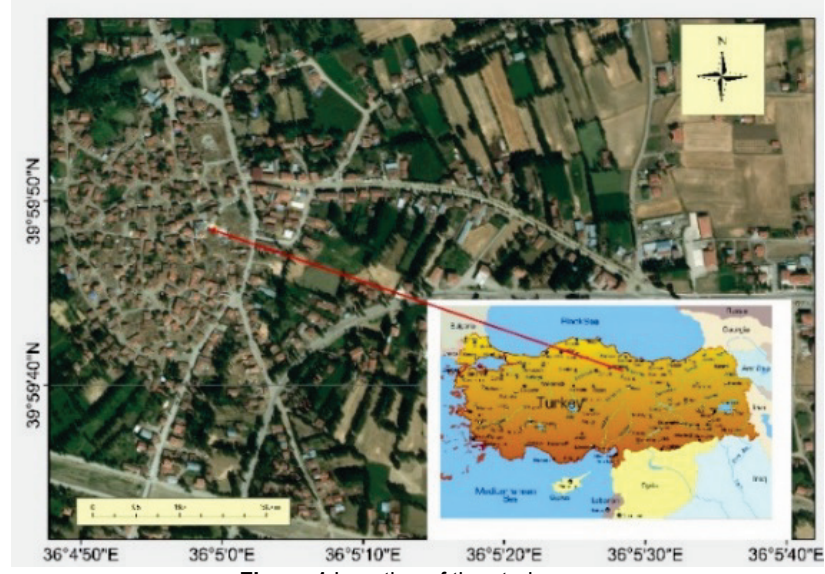

Figure 1 Location of the study area

The test area has an area of approximately 0.27 hectares and is approximately square. It is believed that more than 60000 people once lived in the city and, therefore, there are many architectural pieces in the city. These antique buildings and pieces show that there was intensive settlement in the city in the Hellenistic, Roman and Byzantium periods [26, 27].

\section{MATERIAL AND METHOD 3.1 UAV and Camera}

The four-rotor quadcopter UAV equipped with a Sony NEX-7 camera, was used for this project. There was a three-axis gimbal for taking pictures from different angles and directions.

A 3DR Pixhawk flight controller and UAV were managed manually. Rising and descending were realized where necessary [26]. During the flight, the camera was set to take pictures every 2 seconds, resulting in more data than 54224 megapixels $(6000 \times 4000)$. All 542 pictures taken in the study area can be calibrated $(100 \%)$. The flight took place on average $20 \mathrm{~m}$ above the surface of the land. Photographs were taken using a Sony Next 7 (6000 $\times 4000$ (24 M)) digital camera [27].

\subsection{Photogrammetric Software}

Pix4Dmapper Pro and Agisoft PhotoScan ${ }^{\circledR}$ software packages were used in the photogrammetric process chains to produce orthophoto and DSM in ITRF datum. To produce a data set, the photos were processed using an ASUS Intel® Core TM i7-5820K CPU @ 3.30GHz 64-bit capable computer. GIS ArcMAP 10.2 software was used to compare the results of the process.

\subsection{Pix4 Dmapper}

Pix4Dmapper Pro is a software package developed for processing aerial, terrestrial and oblique aerial images. It includes algorithms for the following operations: $(a)$ aerial triangulation, (b) camera calibration, (c) beam block adjustment, $(d)$ point cloud generation, $(e)$ condensation and $(f)$ filtering [34]. It transforms aerial imagery into precise, georeferenced $2 \mathrm{D}$ maps and 3D models. In the first stage, it calculates the important points location in the captured images. Then software applies the Automatic Arial Triangulation (AAT) and Bundle Block Adjustment (BBA) algorithms. Using these algorithms, the locations and directions of the camera are detected. This stage generates a preliminary 3D map of the working area or object. These algorithms are customizable, topical, implement, and include a wide variety of applications and software. Derived from overlapped images, the $3 \mathrm{D}$ point cloud gives the precise location of the reconstructed workspace.

Digital models that produce the height of each pixel with or without above-ground objects are obtained. A highresolution map of each pixel of the original images is accurately projected onto the digital surface model and produces the correct geographic location without perspective distortions. A full 3D triangle network with photorealistic texture is ideal for sharing and viewing [28].

\subsection{Agisoft Photo Scan}

AgiSoft ${ }^{\circledR}$ PhotoScan is software used for photogrammetric processing of digital images, the production of 3D spatial data used in cultural heritage documents, the production of visual effects and indirect measurements of various objects. It is a cleverly applied digital photogrammetry technique applied using wise vision methods. It is therefore an intelligent automated processing system that can be managed by people new to the field of photogrammetry. However, an expert can adjust the workflow to suit various special tasks and different types of data. In many case studies, it has proven to be a form of software that produces high quality and accurate results. The aim is thus to create a textured $3 \mathrm{D}$ model from photos processed using PhotoScan. The processing of photographs and the creation of $3 \mathrm{D}$ models consists of four main stages. The first of these is camera alignment and the second involves building dense point cloud. The third stage is that of building mesh. After geometry is reconstructed (mesh), it can be textured and used for orthomosaic and DEM generation. Orthomosaic outputs can be obtained in GeoTIFF, JPG, PNG and BMP formats, and DEM outputs can be obtained in GeoTIFF elevation (*.tif), XYZ (*.xyz) and Sputnik KMZ (*.kmz) formats [29].

\subsection{GNSS Receiver}

Trimble R10 surveying instrument delivers major advancements in GNSS performance, safety and productivity in the field. It uses Trimble 360 technology to provide more than 400 individual GNSS channels.

The receiver can track signals from existing and planned GNSS constellations from three GNSS systems. In addition, it can utilize Augmentation Systems.

While RTK is used in difficult areas, interruptions to radio or cellular data connections can disrupt the flow of RTK correction data for single-base or VRS TM Network 
RTK. It includes $x$ Fill ${ }^{\mathrm{TM}}$ support as a standard feature to help overcome these obstacles [30].

\subsection{Ground Control Points and Sample Points}

A total of nine GCPs were used for the block adjustment and to compute georeferenced orthophotos and the DSM. Absolute accuracy was tested with 35 sample points (SPs) that were established in the study area (Fig. 2). Red-white painted metal plates were used as GCPs and SPs.

A Fast Static GNSS survey was made to determine the 3D location of 9 GCPs. Each GCP was observed for 20 minutes in fast static GNSS mode, using three Trimble R10 GNSS instruments. This allowed us to obtain valid horizontal coordinates with an accuracy of $3 \mathrm{~mm}+0,5 \mathrm{ppm}$ RMS precision in a horizontal and $5 \mathrm{~mm}+0,5 \mathrm{ppm}$ RMS precision in a vertical position in fast static surveying. GNSS signals were processed using Leica Geo Office (LGO 2.0) software to find precise coordinates of the GCPs.

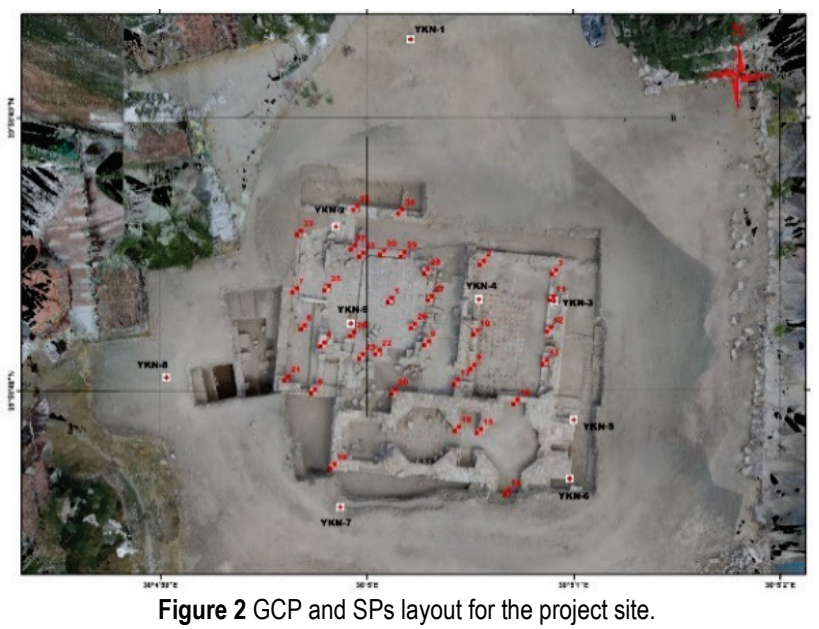

The good distribution of GCPs in the work area is necessary not only for the orientation of images, but also to eliminate the deformation effect caused by systematic errors that occur in camera calibration. [31]. As a result of fast static adjustment, horizontal accuracy was calculated as $0.01 \mathrm{~m}$ and vertical accuracy as $0.03 \mathrm{~m}$.

One of the GCPs was used as a reference point for RTK observations of 35 sample points. SPs were observed in RTK mode for 5 seconds from the base station. RTK is a relative positioning technique that uses at least two GNSS receivers; one is setup on a point as a base station with known coordinates, while the other is a rover. The error value is the difference between the known coordinates of a point and the coordinates obtained from the measurements.

In this study, the coordinate values of the points whose coordinates are determined by static measurements and the coordinate values obtained as a result of photogrammetric evaluations are compared. Since ellipsoidal heights $(h)$ can be obtained from GNSS measurements, heights have been converted into orthometric heights $(H)$. The ellipsoidal height is a geometric height and does not make sense for engineering problems. For this reason, the geometric height must be converted to the orthometric height, which is the physical height. In this application, orthometric height was used.

The application results of GNSS revealed that if enough satellites are above the station point, the horizontal sensitivity is 1.5 to 2 times higher than the vertical sensitivity level [32]. According to the manual of Trimble R10 GNSS device; RTK performance is $\pm 8 \mathrm{~mm}+1 \mathrm{ppm}$ RMS in the horizontal position and $\pm 15 \mathrm{~mm}+1$ ppm RMS in the vertical position. The coordinates of the SPs were calculated by taking the average of the two observations made in 5 seconds with a recording interval of 1 second. Coordinates of 35 SPs were presented in the Tab. 1.

\subsection{Flight}

In this study, a quad-rotor UAV system was used to obtain high-resolution images of the study area. The UAV was primarily controlled manually to better view all the surfaces of the historic area walls. However, as is known, manual flights require a high level of pilot skills, and range restrictions limit the range of operation to several hundred meters. Observation directions for the study area, departure and landing were determined and flight planning was made. To provide a desired location resolution of $0.02 \mathrm{~m}$ and less, the flight height was planned to be approximately $\sim 20 \mathrm{~m}$ and the overlap rates were $80 \%$ overlapping and $70 \%$ sidelap covering. The flight was carried at one of the highest points of the study area. The flight lasted approximately 40 minutes. According to calculations performed in Pix4D and Agisoft the GSD of the data is approximately $0.42 \mathrm{~cm}$ and $0.401 \mathrm{~cm}$ respectively.

\section{PROCESSING}

The Agisoft and Pix4Dmapper software were used for all data processing. ArcMAP 10.2 GIS software was used for topographical analyses. The images captured from the multirotor were imported to the software and then merged. Pix4D used the Initial Processing tool but Agisoft used Align Photos. In both cases, it was possible to set the image size to which the similarity points were searched.

There are three levels of accuracy (low, medium and high). These functions determine the internal and external orientation parameters of the images. In the first step, a digital terrain model (DTM) is generated and then the images can be projected onto the surface of the DTM. In a final step, the orthographic re-projection of the tissue can be applied [33, 34].

In the first stage of the process, the internal camera calibration parameters, the relative camera position and orientation corresponding to each picture and the 3D relative coordinates of the sparse point cloud of the terrain are obtained. In the second step, the point cloud is condensed, and a detailed 3D model of the land is obtained. Before this stage, the obtained point cloud is coordinated using the known coordinates of the GCPs and SPs measured. In the third step, a grid DSM can be generated at a given grid size and the orthophoto is exported at a preselected resolution [35].

In this study, the same GCPs and SPs were selected and marked. 35 SPs were created and marked on the photos in their location. At the end of the processing stage, coordinates of the points were obtained from both software programs. Using both software programs, the process was carried out twice in high and low quality. The results of the Agisoft and Pix4D software programs in high- and low- 
quality mode processing are presented in Tab. 1.

Table 1 The coordinates of the SPs measured and coordinate differences of the calculated from the software programs.

\begin{tabular}{|c|c|c|c|c|c|c|c|c|c|}
\hline PN & $Y / \mathrm{m}$ & $X / \mathrm{m}$ & $H / \mathrm{m}$ & $E_{y} / \mathrm{mm}$ & $E_{x} / \mathrm{mm}$ & $E_{H} / \mathrm{mm}$ & $E_{y} / \mathrm{mm}$ & $E_{x} / \mathrm{mm}$ & $E_{H} / \mathrm{mm}$ \\
\hline 1 & 507118934 & 4429172.434 & 1062.60 & 20.9 & 20.9 & 40.0 & -1.8 & -21.7 & 0.0 \\
\hline 2 & 507129477 & 4429176692 & 1062.17 & 17.4 & 33.5 & 10.0 & -17.8 & $7.2-$ & 10.0 \\
\hline 3 & 507137714 & 4429175657 & 1061.89 & -6.3 & 20.1 & 10.0 & -25.9 & 25.3 & 0.0 \\
\hline 4 & 507111150 & 4429167516 & 1064.76 & 23.0 & 8.7 & 10.0 & 1.4 & 13.6 & 10.0 \\
\hline 5 & 507110130 & 4429162164 & 1065.01 & 18.8 & 23.4 & 10.0 & -1.2 & 3.4 & -10.0 \\
\hline 6 & 507123151 & 4429167626 & 1064.25 & 21.4 & 33.6 & 30.0 & 20.5 & -7.6 & 15.0 \\
\hline 7 & 507107982 & 4429173598 & 1062.97 & 11.4 & 23.3 & 30.0 & -2.6 & 13.5 & -10.0 \\
\hline 8 & 507108898 & 4429169427 & 1062.51 & 14.2 & 15.7 & 30.0 & 3.0 & -11.3 & -10.0 \\
\hline 9 & 507128381 & 4429164958 & 1062.23 & 18.6 & 24.1 & 30.0 & -0.6 & -4.9 & 10.0 \\
\hline 10 & 507128787 & 4429168831 & 1062.22 & 17.0 & 28.5 & 10.0 & -7.0 & -4.9 & -10.0 \\
\hline 11 & 507137525 & 4429172654 & 1062.63 & 6.4 & 31.5 & 0.0 & 6.3 & -19.0 & 20.0 \\
\hline 12 & 507137184 & 4429169150 & 1062.65 & 22.6 & 23.0 & 20.0 & -4.8 & -5.0 & 0.0 \\
\hline 13 & 507136681 & 4429165458 & 1062.54 & 14.0 & 13.7 & 10.0 & 0.4 & -1.1 & 10.0 \\
\hline 14 & 507132338 & 4429150750 & 1061.68 & 18.3 & 23.0 & 20.0 & 1.0 & 10.3 & -20.0 \\
\hline 15 & 507129143 & 4429157654 & 1063.08 & 23.0 & 14.1 & 10.0 & 4.1 & 3.3 & 10.0 \\
\hline 16 & 507133365 & 4429160979 & 1061.64 & 18.2 & -1.7 & 20.0 & -7.9 & 0.4 & 10.0 \\
\hline 17 & 507126517 & 4429163202 & 1064.40 & 28.1 & 6.4 & 20.0 & -6.7 & 7.6 & 10.0 \\
\hline 18 & 507126629 & 4429157908 & 1063.26 & 24.5 & 10.6 & 10.0 & -1.1 & 5.4 & -25.0 \\
\hline 19 & 507112332 & 4429153661 & 1065.15 & 13.4 & 23.1 & 10.0 & -5.8 & -4.3 & 10.0 \\
\hline 20 & 507119374 & 4429162135 & 1064.81 & 30.3 & 24.3 & 20.0 & 8.1 & -13.6 & -20.0 \\
\hline 21 & 507107073 & 4429163606 & 1062.88 & 17.3 & 21.4 & 10.0 & 0.9 & 0.9 & 20.0 \\
\hline 22 & 507117484 & 4429166589 & 1062.84 & 40.5 & 12.4 & 20.0 & -1.7 & 3.0 & 25.0 \\
\hline 23 & 507115626 & 4429166097 & 1062.59 & 27.2 & 8.4 & 20.0 & 2.6 & 3.0 & 10.0 \\
\hline 24 & 507114606 & 4429168622 & 1062.17 & 13.3 & 27.6 & 30.0 & -1.4 & 4.1 & 10.0 \\
\hline 25 & 507111652 & 4429173819 & 1062.63 & 18.9 & 25.4 & 20.0 & -8.6 & 3.3 & 10.0 \\
\hline 26 & 507121585 & 4429169582 & 1063.08 & 19.4 & 15.1 & 30.0 & 10.3 & 4.3 & -20.0 \\
\hline 27 & 507123532 & 4429172662 & 1062.58 & 13.0 & 15.1 & 10.0 & 7.2 & -11.6 & 20.0 \\
\hline 28 & 507123081 & 4429175705 & 1064.09 & 24.1 & 23.3 & 30.0 & -2.7 & 1.4 & -10.0 \\
\hline 29 & 507120373 & 4429177647 & 1062.30 & 2.2 & 27.2 & 20.0 & -6.6 & 3.1 & -10.0 \\
\hline 30 & 507118029 & 4429177803 & 1062.34 & 21.0 & 30.3 & 20.0 & 3.0 & -5.9 & -10.0 \\
\hline 31 & 507115641 & 4429177607 & 1062.16 & 12.1 & 20.4 & 30.0 & -6.0 & -6.3 & -10.0 \\
\hline 32 & 507114671 & 4429178415 & 1063.70 & 20.4 & 18.9 & 30.0 & -3.0 & 8.5 & -10.0 \\
\hline 33 & 507108456 & 4429180058 & 1062.98 & 15.2 & 15.0 & 20.0 & -26.3 & 0.1 & -10.0 \\
\hline 34 & 507120104 & 4429182445 & 1063.41 & 26.3 & 1.0 & 20.0 & 4.5 & -9.4 & -10.0 \\
\hline \multirow[t]{5}{*}{35} & 507114942 & 4429182877 & 1063.94 & -5.9 & 45.3 & 20.0 & -13.6 & 11.5 & -20.0 \\
\hline & & & Average & 17.7 & 20.2 & 19.4 & -2.3 & 0.2 & -0.7 \\
\hline & & & Maximum & 40.5 & 45.3 & 40.0 & 20.5 & 25.3 & 25.0 \\
\hline & & & Minimum & -6.3 & -1.7 & 0.0 & -26.3 & -21.7 & -25.0 \\
\hline & & & RMSE & 20.0 & 22.3 & 21.4 & 9.3 & 9.5 & 13.6 \\
\hline
\end{tabular}
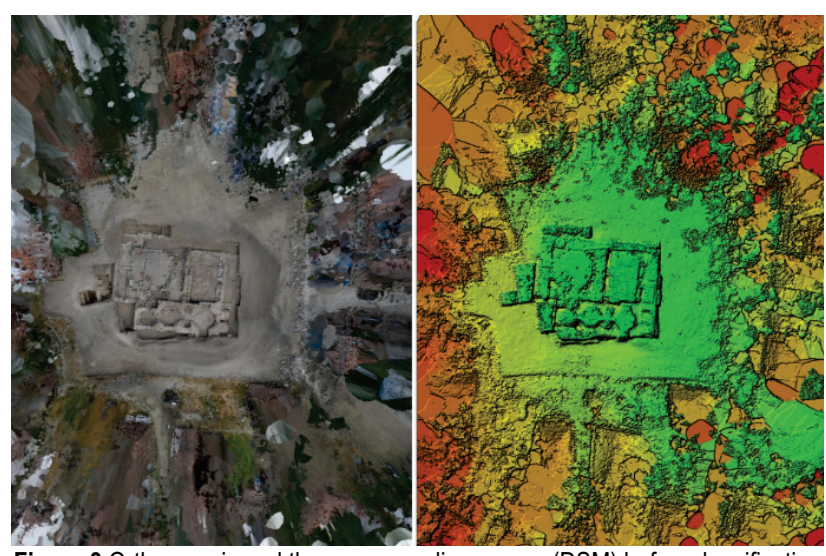

Figure 3 Orthomosaic and the corresponding sparse (DSM) before densification

In this study, 9 GCPs and 35 SPs were used for georeferencing. Coordinates of the dense point cloud were obtained from the photogrammetric process and were referred to as UTM Zone 36 (ETRS89) and the elevation at Mean Sea Level (MSL) using the EGM08 geoid model. The coordinates of the 35 SPs, whose coordinates were measured by RTK GNSS observation, were compared with the coordinate values obtained from both software programs (Agisoft and Pix4D) as a result of the intensive and low-density process. A number of overlapping images were computed for each pixel of orthomosaic in Agisoft processing and are submitted in Fig. 3. The green areas indicate an overlap of over 5 images for every pixel.

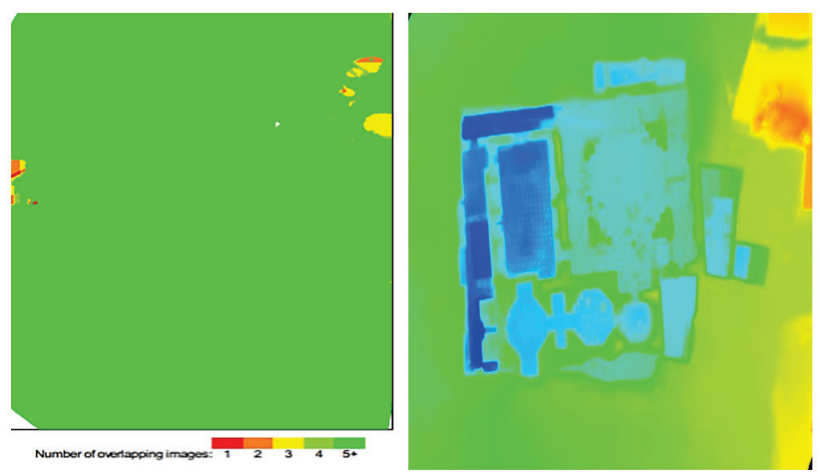

Figure 4 The number of overlapping images computed for each pixel of the orthomosaic and DSM

\section{RESULTS}

The mean RMSEs of the models were reported by the software as $\pm 2.2 \mathrm{~cm}$ between the computed and measured coordinates of the 9 GCPs. The individual RMSEs for the $R M S E_{Y}, R M S E_{X}$ and $R M S E_{H}$ were $\pm 2.43, \pm 2.01 \mathrm{~cm}$ and $\pm 2.52 \mathrm{~cm}$, respectively, and totaled $4.03 \mathrm{~cm}$. The GSD value was calculated as $0.401 \mathrm{~cm} /$ pixel with the Agisoft software, while the PixD software was $0.420 \mathrm{~cm} /$ pixel. 
The DSM and orthomosaic resolution was $1 \times$ GSD $(0.425 \mathrm{~cm} / \mathrm{pixel})$ and the DTM resolution was $5 \times \mathrm{GSD}$ $(0.425 \mathrm{~cm} / \mathrm{pixel})$ in Pix 4D. The DSM and orthomosaic resolution was $1 \times \mathrm{GSD}(0.401 \mathrm{~cm} /$ pixel $)$, DTM resolution was $0.802 \mathrm{~cm} /$ pixel.

The orthophoto and DSM were produced from highresolution UAV images, covering the study area, using Agisoft Photoscan and Pix4Dmapper Pro software. Aerial photographs were taken at heights of between $15-20 \mathrm{~m}$ with $80 \%$ overlapping and $70 \%$ sidelap covering and were scaled by precisely coordinated GCPs using static GNSS observations.

The RMSE of the 9 GCPs were reported by Pix 4D software, respectively, as $R M S E_{Y}, R M S E_{x}$ and $R M S E_{H}$ were $\pm 2.23 \mathrm{~cm}, \pm 2,90 \mathrm{~cm}$ and $\pm 3,05 \mathrm{~cm}$, respectively.

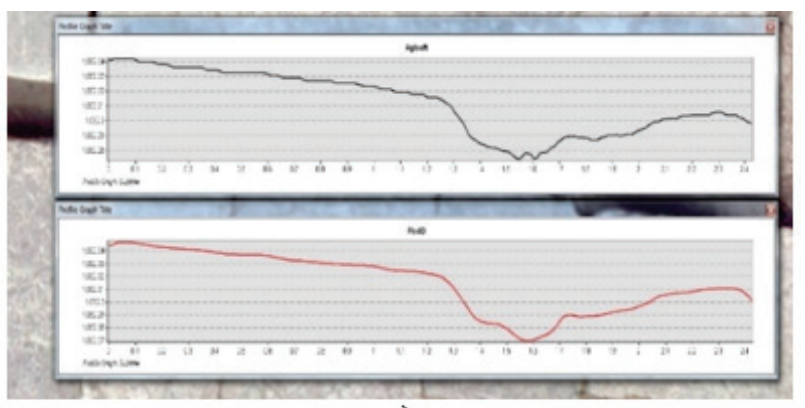

a)

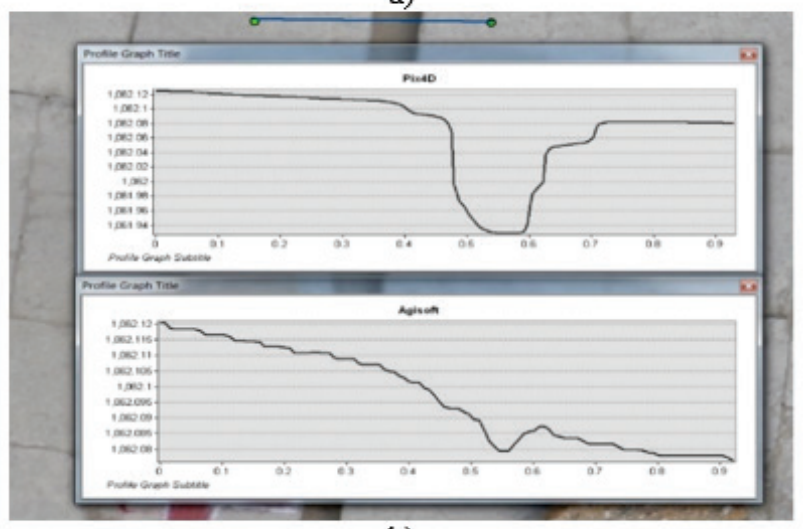

b)

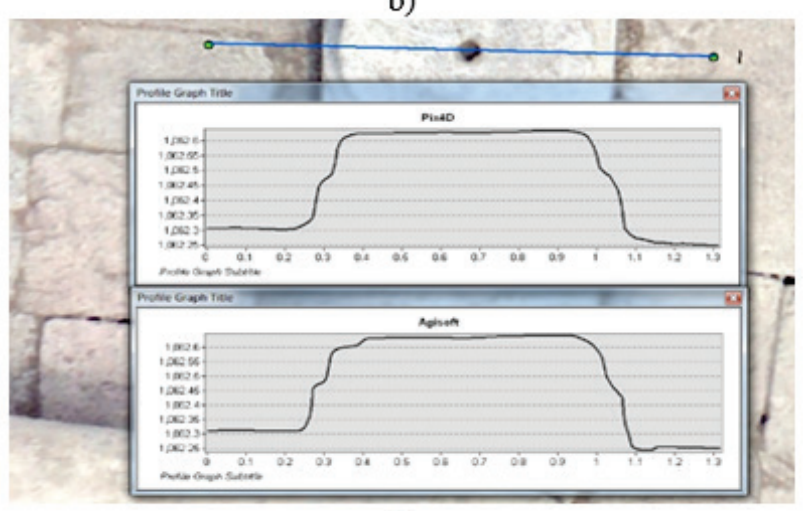

c)

Figure 5 Cross sections obtained from DSM (units are in meters, both elevation and distance). a) Cross sections from flat surface, b) Cross sections from upward, c) Cross sections from channel surfaces

The Reconstructed Digital Elevation Models Resolution was $8.02 \mathrm{~mm} /$ pix and the point density was 1.55 points $/ \mathrm{cm}^{2}$ in Agisoft high quality processing. The Reconstructed Digital Elevation Models Resolution was $3.24 \mathrm{~cm} /$ pix and point density was 951 points $/ \mathrm{m}^{2}$ in Agisoft low quality processing.
For every SP, the assessment of accuracy in east $(Y)$, north $(X)$, and height $(H)$ was performed by comparing the SPs measured coordinates with the interpolated coordinates from the four nearest points of the dense cloud generated by the photogrammetric process, resulting in $R M S E_{Y}, R M S E_{X}$, and $R M S E_{H}$ accuracy measures, respectively.

As a result of high quality Agisoft processing, RMSEs values of the coordinate differences obtained from 35 SPs were calculated respectively as $R M S E_{Y}=2.07 \mathrm{~cm}, R M S E_{x}$ $=2.12 \mathrm{~cm}$ and $R M S E_{H}=3.98 \mathrm{~cm}$. As a result of high quality Pix4D processing, RMSEs values of the coordinate differences obtained from 35 SPs were calculated respectively as $R M S E_{Y}=1,77 \mathrm{~cm}, R M S E_{x}=2.02 \mathrm{~cm}$ and $R M S E_{H}=1.94 \mathrm{~cm}$. As a result of high quality Pix 4D and Agisoft processing, RMSEs values of the coordinate differences obtained from 35 SPs were calculated respectively as $R M S E_{Y}=9.3 \mathrm{~mm}, R M S E_{x}=9.5 \mathrm{~mm}$ and $R M S E_{H}=13.6 \mathrm{~mm}$. As a result of high quality and low quality Agisoft processing, RMSEs values of the coordinate differences obtained from 35 SPs were calculated respectively as $R M S E_{Y}=20.8 \mathrm{~mm}, R M S E_{x}=$ $26.6 \mathrm{~mm}$ and $R M S E_{H}=66.1 \mathrm{~mm}$.

In addition, cross sections from three different regions were extracted and compared on digital terrain models produced using two software programs. In the cross sections taken from both software packages using DSMs, there was no difference in the flat surfaces and upward sections. However, in the sections taken down from the surface, Agisoft was unsuccessful (Fig. 5).

Comparing the cross sections obtained from the DSMs obtained from the two software programs, it was seen that the Pix4D software was more successful than Agisoft, especially in the sections produced from surfaces, such as ducts and pits. Therefore, we can say that the Pix4D is successful in the modeling of canals, valleys and pits.

\section{CONCLUSION}

Among the measurement methods used to document objects on the Earth, the most commonly used methods are the classical terrestrial survey method, GNSS, laser scanning, photogrammetric and remote sensing. These methods differ in accuracy, the hardware and software used, and the properties of the object to be measured. The method chosen to be used mostly varies according to the condition of the object to be measured (width, whether reachable, how much vegetation, and whether there is sludge, etc) and the desired sensitivity. In some cases, if the visual output is desired rather than the location information of the objects, such as orthophoto map, satellite image, then direct photogrammetric and remote sensing methods are preferred. Unmanned Aerial Vehicles present clear advantages over piloted aircrafts, satellites and traditional surveying methods, particularly because of their low cost, operational flexibility, and better spatial and temporal resolution and UAVs require less time than other techniques for data acquisition and, for this reason, it reduces costs. There have been great developments in UAV photogrammetry in recent years and increasingly it has been used in situations where classical photogrammetry is less efficient or not applicable. These areas, of course, include archaeological and historical sites. 
This study was carried out in order to obtain accuracy in horizontal and vertical $\mathrm{cm}$ precision in an archaeological area by using GCP points, which were well dispersed in the study area and with very sensitive GCP points. For this study, 542 high-resolution images were captured with the UAV from approximately $20 \mathrm{~m}$ high. The high-resolution images were processed using Agisoft Photoscan and Pix4Dmapper Pro software programs to generate point clouds and DSMs. Both software packages produced GSD values of $0.42 \mathrm{~cm} /$ pixel.

The mean RMSE of the models were reported by the software as $\pm 2.2 \mathrm{~cm}$ between the computed and measured coordinates of the 9 GCPs. The individual RMSEs for the $R M S E_{Y}, R M S E_{X}$ and $R M S E_{H}$ were $\pm 2.43, \pm 2.01 \mathrm{~cm}$ and $\pm 2.52 \mathrm{~cm}$, respectively, and totaled $4.03 \mathrm{~cm}$.

At the 9 GCP locations, the locations of which were determined by GNSS measures, the GSD value was calculated as $0.401 \mathrm{~cm} /$ pixel with the Agisoft software, while the PixD software calculated it as $0.420 \mathrm{~cm} /$ pixel.

The DSM and orthomosaic resolution was $1 \times$ GSD $(0.420 \mathrm{~cm} /$ pixel $)$ DTM resolution was $5 \times$ GSD $(0.420$ $\mathrm{cm} /$ pixel) in Pix4D. The DSM and orthomosaic resolution was $1 \times \operatorname{GSD}(0.401 \mathrm{~cm} /$ pixel $)$, DTM resolution was 0.802 $\mathrm{cm} /$ pixel.

Subtracting sections from three different regions compared the topographic structure of the DSMs produced from both software packages. The flat terrain and the upward-rising sections were very close to each other. However, it was seen that the section produced from the Agisoft software did not reflect the surface in the sections down the surface. It was seen that the cross section produced from Pix4D was in conflict with the actual measurements. In this case, while there was no big difference between the DSMs produced by Agisoft and Pix4D software in the horizontal position in the processes with the same density, it can be said that Pix4D was more successful in the vertical position.

\section{REFERENCES}

[1] Remondino, F. \& El-Hakim, S. (2006). Image-based 3D modelling. The Photogrammetric Record, 21, 269-291. https://doi.org/10.1111/j.1477-9730.2006.00383.x

[2] Nex, F. \& Remondino, F. (2014). UAV for 3D mapping application. A review.Appl. Geomat, 2014(6), 1-15. https://doi.org/10.1007/s12518-013-0120-x

[3] Nebiker, S., Annen, A., Scherrer, M., \& Oesch, D. (2008). A light-weight multispectral sensor for micro UAV Opportunities for very high resolution airborne remote sensing. In International Archives of the Photogrammetry, Remote Sensing and Spatial Information Sciences; International Society for Photogrammetry and Remote Sensing (ISPRS). 37(B1).

[4] Hugenholtz, C. H., Whitehead, K., Brown, O. W., Barchyn, T. W., Moorman, B., Clair, A. L., Riddell, K., \& Hamilton, T. (2013). Geomorphological mapping with a small unmanned aircraft system (sUAS): Feature detection and accuracy assessment of a photogrammetrically-derived digital terrain model. Geomorphology 194(2013) 16-24. https://doi.org/10.1016/j.geomorph.2013.03.023

[5] Kršák, B., Blištan, P., Pauliková, A., Puškárová, P., Kovanic, L., Palková, J., \& Zelizn aková, V. (2016). Use of low-cost UAV photogrammetry to analyze the accuracy of a digital elevation model in a case study. Measurement, 91(2016) 276-287. https://doi.org/10.1016/j.measurement.2016.05.028
[6] Themistocleous, K., Papadavid, G., Michaelides, S,Ambrosia, V., \& Hadjimitsis, D. G. (2019). Local monitoring techniques for cultural heritage sites affected by geo-hazards. Eds. Proc. of SPIE, 10773. https://doi.org/10.1117/12.2503914

[7] Alidost, F. \& Arafi, H. (2017). Comparison of UAS based Photogrammetry software for 3D pint cloud generation: A Survey over a historical site. ISPRS Annals of the Photogrammetry, Remote Sensing and Spatial Information Sci, IV-4/W4, $20174^{\text {th }}$ International GeoAdvances Workshop, 14-15 October 2017, Karabuk, Turkey. https://doi.org/10.5194/isprs-annals-IV-4-W4-55-2017

[8] Themistocleous, K., Agapiou, A., King, H. M., King, N., \& Hadjimitsis, D. G. (2014). More Than a Flight: The Extensive Contributions of UAV Flights to Archaeological Research. The Case Study of Curium Site in Cyprus. Proc. EuroMed 2014 Conference, 3-8 November 2014. 2014a.

[9] Woodget, A. S., Carbonneau, P. E., Visser, F., \& Maddock, I. P. (2015). Quantifying submerged fluvial topography using hyperspatial resolution UAS imagery and structure from motion photogrammetry. Earth Surf. Proc. Landforms, 40(1), 47-64. https://doi.org/10.1002/esp.3613

[10] Ablanedo, E. S., Chandler, J. H., Rodríguez-Pérez, JR., \& Ordóñez, C. (2018). Accuracy of Unmanned Aerial Vehicle (UAV) and SfM Photogrammetry Survey as a Function of the Number and Location of Ground Control Points Used Remote Sens. 2018, 10, 1606. https://doi.org/10.3390/rs10101606

[11] Lin, A. Y-M., Novo, A., Har-Noy, S., Ricklin, N. D., \& Stamatiou, K. (2011). Combining GeoEye-1 Satellite Remote Sensing, UAV Aerial Imaging, and Geophysical Surveys in Anomaly Detection Applied to Archaeology. IEEE Journal of Selected Topics in Applied Earth Observations and Remote Sensing, 4(4), 870-876. https://doi.org/10.1109/JSTARS.2011.2143696

[12] Heritage, G. L. \& Large, A. R. G. (2009). Laser Scanning for the Environmental Sciences. John Wiley \& Sons Ltd, the Atrium, Southern Gate Chichester, West Sussex, UK, ISBN 978-1-4051-5717-9. https://doi.org/10.1016/j.geomorph.2009.03.021

[13] Malinowski, R., Höfle, B., Koenig, K., Groom, G., Schwanghart, W., \& Heckrath, G. (2016). Local-scale flood mapping on vegetated floodplains from radiometrically calibrated airborne LiDAR data. ISPRS Journal of Photogrammetry and Remote Sensing, 119, 267-279 https://doi.org/10.1016/j.isprsjprs.2016.06.009

[14] Guindon, B. (2014). Computer-Based Aerial Image Understanding: A Review and Assessment of its Application to Planimetric Information Extraction from Very HighResolution Satellite Images. Canadian Journal of Remote Sensing, 23(1). https://doi.org/10.1080/07038992.1997.10874676

[15] Küng, O., Strecha, C., Beyeler, A., Zufferey, J.-C., Floreano, D., Fua, P., \& Gervaix, F. (2011). The accuracy of automatic photogrammetric techniques on ultra-light UAV imagery. Int. Arch. Photogramm. Remote Sens., 38, 125-130. https://doi.org/10.5194/isprsarchives-XXXVIII-1-C22-125-2011

[16] Anderson, K. \& Gaston, K. J. (2013). Lightweight unmanned aerial vehicles will revolutionize spatial ecology. Frontiers in Ecology and the Environment, 11, 138-146. https://doi.org/10.1890/120150

[17] Lichti, D., Brüstle, S., \& Franke, J. (2007). Self-Calibration and Analysis of the Surphaser Hemispherical 3D Scanner. FIGURE Working Week, Hong Kong SAR, China.

[18] Harwin, S. \& Lucieer, A. (2012). Assessing the accuracy of georeferenced point clouds produced via multi-view stereopsis from unmanned aerial vehicle (UAV) imagery. Remote Sens. 2012(4), 1573-1599. https://doi.org/10.3390/rs4061573 
[19] Jaud, M., Passot, S., Bivic, L. R., Delacourt, C., Grandjean, P., \& Dantec, N. L. (2016). Assessing the Accuracy of HighResolution Digital Surface Models Computed by PhotoScan ${ }^{\circledR}$ and MicMac ${ }^{\circledR}$ in Sub-Optimal Survey Conditions. Remote Sens., 8(6), 465. https://doi.org/10.3390/rs8060465

[20] Docci, M. \& Maestri, D. (2009). Manuale di rilevamento architettonico e urbano, Data di pubblicazione: 17 Settembre 2009, Lunghezza stampa: 374 Lingua: Italiano.

[21] Canciani, M., Falcolini, C., \& Saccone, M. (2013). Spadafora aInternational Archives of the Photo. Remote Sensing and Spatial Information Sciences, XL-5/W1, 2013 3D-ARCH 2013-3D Virtual Reconstruction and Visualization of Complex Architectures, 25-26 February 2013, Trento, Italy https://doi.org/10.5194/isprsarchives-XL-5-W1-27-2013

[22] De Reu, J., De Smedt, P., Herremans, D., Meirvenne, M. V., Laloo, P., \& Clercq, W.D. (2014). On introducing an imagebased 3D reconstruction method in archaeological excavation practice. Journal of Archaeological Science, 41(2014) 251-262. https://doi.org/10.1016/j.jas.2013.08.020

[23] Doneus, M., Verhoeven, G., Fera, M., Briese, C., Kucera, M., \& Neubauer, W. (2011). From deposit to point cloud a study of low-cost computer vision approaches for the straightforward documentation of archaeological excavations. In: Cepek, A. (Ed.), XXIIIrd Int. CIPA Symposium, Prague, 12-16 September 2011, Geoinformatics, 6. Faculty of Civil Engineering, Czech Technical University, Prague, pp. 81-88. https://doi.org/10.14311/gi.6.11

[24] Pavlidis, G., Koutsoudis, A., Arnaoutoglou, F., Tsioukas, V., \& Chamzas, C. (2007). Methods for 3D digitization of cultural heritage. Journal of Cult. Herit., 8(1), 93-98. https://doi.org/10.1002/rra.2687

[25] Lucieer, A., Jong, S. M., \& Turner, D. (2014). Mapping landslide displacements using Structure from Motion (SfM) and image correlation of multi-temporal UAV photography. Prog. Phys. Geogr., 38(2014), 97-116. https://doi.org/10.1177/0309133313515293

[26] Alkan, A. (2004). Sebastiapolis Antik City. University of Ankara. Master These.; 2014: 10.1501/ Ankara, Turkey3284

[27] Susam, T. (2019). Topographical Analyses of Unmanned Aerial Vehicle-Based Very High-Resolution Digital Surface Models for Archaeological Sites. Tehnički vjesnik, 26(1), 236-242. https://doi.org/10.17559/TV-20171109090111

[28] Pix4D. (2017). Pix4Dmapper 3.2 User Manual; https://support.pix4d.com/hc/en-us/sections/200591059Manual

[29] Agisoft, L. Agisoft Photoscan Professional v1.4.3; Agisoft LLC: St. Petersburg, Russia, 2018. https://www.agisoft.com/pdf/photoscan-pro_1_4_en.pdf

[30] Trimble; (2017): https://www.trimble.com/LS_ Receiver Help /V5.11/en/R10\%20UserGuide.pdf

[31] Gerke, M. \& Przybilla, H. J. (2016). Accuracy Analysis of Photogrammetric UAV Image Blocks: Influence of Onboard RTK-GNSS and Cross Flight Designs. Photogrammetrie Fernerkundung - Geoinformation, 2016(1), 17-30. https://doi.org/10.1127/pfg/2016/0284

[32] Arslanoglu, M. (2002). Investigation of usability of real-time kinematic GPS in urban information system. Master of Science Thesis, Zonguldak Karaelmas University, Graduate School of Natural and Applied Sciences.

[33] Wiesel, J. (1985). Digital image processing for orthophoto generation. Photogrammetria, 40(2), 69-76. https://doi.org/10.1016/0031-8663(85)90001-8

[34] Niethammer, U., James, M. R., Rothmund, S., Travelletti, J., \& Joswig, W. (2012). UAV-based remote sensing of the Super Sauze landslide: evaluation and results. Eng. Geology, 128, 2-11. https://doi.org/10.1016/j.enggeo.2011.03.012
[35] Rosnell, T. \& Honkavaara, E. (2012). Point cloud generation from aerial image data acquired by a quadrocopter type micro unmanned aerial vehicle and a digital still camera, Sensors, 12(2012), 453-480. https://doi.org/10.3390/s120100453

\section{Contact information:}

Servet YAPRAK, Assistant Prof. Dr.

(Corresponding author)

Gaziosmanpasa University, Department of Geomatics,

Taslıciftlik Campus, 60100, Tokat-Turkey

E-mail: servet.yaprak@gop.edu.tr 